\title{
In-Plane Cracking Behavior and Ultimate Strength for 2D Woven and Braided Melt-Infiltrated SiC/SiC Composites Tensile Loaded in Off-Axis Fiber Directions
}

Gregory N. Morscher; Ohio Aerospace Institute, Cleveland, $\mathrm{OH}$

Hee Mann Yun; Matech GSM, CA

James A. DiCarlo; NASA Glenn Research Center, Cleveland, OH

\begin{abstract}
The tensile mechanical properties of ceramic matrix composites (CMC) in directions off the primary axes of the reinforcing fibers are important for architectural design of CMC components that are subjected to multi-axial stress states. In this study, 2D-woven meltinfiltrated (MI) $\mathrm{SiC} / \mathrm{SiC}$ composite panels with balanced fiber content in the $0^{\circ}$ and $90^{\circ}$ directions were tensile loaded in-plane in the $0^{\circ}$ direction and at $45^{\circ}$ to this direction. In addition, a 2D triaxially-braided MI composite panel with balanced fiber content in the $+/-67^{\circ}$ bias directions and reduced fiber content in the axial direction was tensile loaded perpendicular to the axial direction tows (i.e., $23^{\circ}$ from the bias fibers). Stress-strain behavior, acoustic emission, and optical microscopy were used to quantify stressdependent matrix cracking and ultimate strength in the panels. It was observed that both off-axis loaded panels displayed higher composite onset stresses for through-thickness matrix cracking than the $2 \mathrm{D}$-woven $0 / 90$ panels loaded in the primary $0^{\circ}$ direction. These improvements for off-axis cracking strength can in part be attributed to higher effective fiber fractions in the loading direction, which in turn reduces internal stresses on critical matrix flaws for a given composite stress. Also for the $0 / 90$ panel loaded in the $45^{\circ}$ direction, an improved distribution of matrix flaws existed due to the absence of fiber tows perpendicular to the loading direction. In addition, for the $+67 / 0 /-67$ braided panel, the axial tows perpendicular to the loading direction were not only low in volume fraction, but were also were well separated from one another. Both off-axis oriented panels also showed relatively good ultimate tensile strength when compared to other offaxis oriented composites in the literature, both on an absolute strength basis as well as when normalized by the average fiber strength within the composites. Initial implications
\end{abstract}


are discussed for constituent and architecture design to improve the directional cracking of $\mathrm{SiC} / \mathrm{SiC} \mathrm{CMC}$ components with MI matrices.

\section{INTRODUCTION}

The tensile mechanical properties of continuous fiber-reinforced ceramic matrix composites $(\mathrm{CMC})$ vary according to the orientation of fibers with respect to the loading axis. CMC mechanical properties are typically measured for tensile stresses in a direction parallel to one of the primary fiber axes, which generally results in desirable linear stress-strain behavior, a high stress for deviation from linearity or DFLS (also referred to as proportional limit stress), and fiber-pullout mechanisms that lead to graceful failure and high ultimate tensile strength or UTS [1]. This is the case because the high-modulus fibers are oriented to carry much of the tensile load applied to the composite prior to and after the DFLS point, which is caused by the development of transverse through-thickness matrix cracks (TTMC) in the CMC. However, when loaded in a direction at a significant angle to the primary fiber axes, large reductions in key CMC design properties can occur such as low DFLS and UTS [2]. Whereas on-axis properties are strongly dependent on the fiber properties, off-axis properties are strongly dependent on the matrix properties, particularly their stiffness and load-carrying ability which is typically related to their porosity content. For example, when CMC with highly porous oxide matrices were tested off-axis, non-linear and relatively weak stress-strain behavior was observed because the porous matrix could not carry significant load [3]. But when the matrix stiffness and load-carrying ability was increased via sintering of the porous matrix, higher DFL stresses and ultimate strengths were obtained, but still not as high as the on-axis value. .

For CMC structural applications, high stresses for generation of TTMC are generally desired in all directions. This not only allows maintenance of composite modulus and thermal conductivity to high stresses, but also results in greater composite life which is particularly important for CMC with non-oxide constituents that can be degraded by environmental permeability into through-thickness matrix cracks. To achieve these high cracking stresses, high-stiffness low-porosity matrices are generally 
preferred, which can also help to improve the CMC creep-rupture resistance and thermal conductivity. One such CMC system is the melt-infiltrated (MI) SiC matrix system reinforced by the Sylramic-iBN SiC fiber that is near-stoichiometric in composition and contains a thin in-situ grown $\mathrm{BN}$ layer on its surface [4]. This $\mathrm{SiC} / \mathrm{SiC}$ composite system is typically processed by taking a woven or braided fiber-preform, coating the fibers with another thin BN layer by chemical vapor infiltration (CVI), and then forming an initial $\mathrm{SiC}$ matrix by CVI. The remaining matrix porosity is then filled with slurry of $\mathrm{SiC}$ particles. After drying the slurry-infiltrated perform, final matrix formation is by melt infiltration (MI) of liquid Si which fills nearly all of the large pores in the structure, leaving $\sim 5 \%$ closed porosity.

The primary objective of this study was to measure and analyze the off-axis inplane tensile stress-strain behavior of five thin-walled panels with the MI SylramiciBN/SiC system and two different basic fiber architectures, A and B. Four panels with architecture A, consisting of a 2D-woven fabric lay-up with balanced fiber content in the $0^{\circ}$ and $90^{\circ}$ directions, were tensile loaded in the $0^{\circ}$ direction (Panels A1-A3) and at $45^{\circ}$ to this direction (Panel A4). This balanced 2D 0/90 architecture is often used for the fabrication of thin-walled CMC components with large radii-of-curvature. Another panel with architecture B (Panel B1), consisting of a 2D triaxially-braided architecture with balanced fiber content in the $+/-67^{\circ}$ bias directions and reduced fiber content in the axial direction, was tensile loaded perpendicular to the axial direction (i.e., $23^{\circ}$ from the bias fibers). Again, this 2D tri-axially braided architecture is often used for the fabrication of thin-walled CMC components with small radii-of-curvature. Thus besides scientific value, tensile testing of these panels in the primary fiber axis as well as in the off-axis directions should also have technical value in that it is a first step in understanding the mechanical and cracking effects of 2D fiber architectures and multi-directional stresses, such as thermal stresses, in these components. The primary room temperature properties of interest were the elastic modulus, the DFLS as measured by two off-set methods, the UTS, and the matrix cracking behavior as monitored by acoustic emission. Initial implications are discussed for architecture design to model and improve the directional cracking strengths of $\mathrm{SiC} / \mathrm{SiC} \mathrm{CMC}$ components with MI matrices. 


\section{EXPERIMENTAL}

For this study, four panels with architecture A were fabricated by cutting $150 \mathrm{x}$ $225 \mathrm{~mm}$ plies from a 2D-woven 0/90 Sylramic SiC fabric* with a five-harness satin weave and balanced tow ends per $\mathrm{cm}(\mathrm{epcm})$ in the $0^{\circ}$ and $90^{\circ}$ directions. Each single tow consisted of $\sim 800$ fibers with a $10 \mu \mathrm{m}$ average diameter. For Panels A1 and A4, the fabric had 8.7 single tow epcm; but the plies were cut along the $0^{\circ}$ and $90^{\circ}$ directions for Panel A1 and at $45^{\circ}$ to the orthogonal directions for Panel A4. For Panels A2 and A3, the plies were cut along the $0^{\circ}$ and $90^{\circ}$ directions; but the fabric had 7.9 single tow epcm for Panel A2 and 3.95 double tow epcm for Panel A3. For each A-type panel, eight plies were then stacked and converted to Sylramic-iBN* fiber at NASA Glenn [5]. The 2D Sylramic-iBN stacks were then sent to GE Composites, Newark, DE, where they went through typical MI processing: CVI BN fiber coating, CVI SiC initial matrix, waterbased slurry SiC particle infiltration, drying, and liquid-Si infiltration [4].

For Panel B1, the architecture was first formed by creating a four-layer $0 / \pm 67$ triaxial braid on a $50 \mathrm{~mm}$ diameter tubular mandrel. Approximately $23 \%$ of the fibers were in the axial direction and $77 \%$ of the fibers were in the bias direction at an angle of $\sim 67^{\circ}$ to the axial fibers. Two as-produced Sylramic fiber tows were combined in the axial and bias directions. A $75 \mathrm{~mm}$ length of the tubular architecture was then removed from the mandrel and laid flat to form a $75 \mathrm{~mm} \mathrm{x} 150 \mathrm{~mm}$ rectangular preform, which was converted to the Sylramic-iBN fibers at NASA and then into a CMC panel with typical MI processing at GE composites.

Tensile 150-mm long dogbone specimens with a contoured gage section (12.7 $\mathrm{mm}$ width in grip region and $10 \mathrm{~mm}$ width in gage region) were machined from each panel. Architecture, thickness, and total fiber volume fraction for all tested specimens from the five panels are listed in Table 1. For Panel A1, A2, and A3 specimens, the testing direction was along the primary or $0^{\circ}$ direction; but for Panel A4, testing was at $45^{\circ}$ to the $0^{\circ}$ and $90^{\circ}$ directions of the original fabric as shown in Fig. 1a. For the Panel B

\footnotetext{
* The Sylramic fibers of this study were originally produced by Dow Corning, Midland, MI and were woven into fabric at Albany International Techniweave, Rochester, NH.. Both the Sylramic and Sylramic-iBN SiC fibers are currently produced at ATK COI Ceramics, San Diego, CA.
} 
specimens, Fig. $1 \mathrm{~b}$ shows that the testing direction was perpendicular to the axial or $0^{\circ}$ fiber direction, or along the "hoop" direction of the original tubular architecture. Thus for both off-axis panels of this study, the tensile loading direction was symmetrically located between the two primary fiber directions that contained equal volume fractions.

Tensile unload-reload hysteresis tests were performed on the dogbone specimens using a universal testing machine (Model 8562, Instron, Ltd., Canton, Mass.) with acoustic emission (AE) monitoring as described in references 6 and 7. A clip-on strain gage (25.4 mm gage, $0.25 \%$ strain) was used to measure strain in the gage section. A Fracture Wave Detector by Digital Wave Corporation (Englewood, $\mathrm{CO}$ ) was used to monitor AE. Three wide-band (B1025, Digital Wave Corporation) AE sensors were mounted on the specimens. Two sensors were placed above and below the gage section approximately $50 \mathrm{~mm}$ apart from one another. The third sensor was placed between the other two sensors in the middle of the gage section. Only events which triggered the middle sensor were used in the analysis, i.e., only events which occurred in the gage section.

The tested specimens were cut and polished along the loading-direction in order to measure transverse matrix cracks optically. The polished specimens had to be plasma etched ( $\mathrm{CF}_{4}$ at 500 Watts for 30 minutes) in order to enhance the matrix cracks in the CVI SiC. Matrix cracks were counted over lengths of approximately $10 \mathrm{~mm}$ in order to obtain a matrix crack density.

\section{RESULTS}

The room-temperature tensile stress-strain curves for the off-axis oriented $\mathrm{SiC} / \mathrm{SiC}$ Panels $\mathrm{A} 4$ and $\mathrm{B} 1$ and for the orthogonal-oriented 2D woven $\mathrm{SiC} / \mathrm{SiC}$ Panels A1-A3 are shown in Figure 2. Hysteresis loops used for residual stress determination have been eliminated from these curves except for a braided Panel B1 specimen which is given as an example in Figure 2. Average values for such key mechanical properties as initial elastic modulus E, UTS, and residual stress on matrix are listed in Table I. As shown in Figure 3, the offset strain construct method [8] was also used to determine the DFL stress (DFLS). It consists of drawing a line with the same slope as the initial elastic modulus, but offset by some amount of positive strain, where the DFLS would be 
determined by the intersection of that curve with the stress-strain curve. Typical offsetstrain values used are $0.005 \%$ [9] and $0.002 \%$ [10]. As indicated in Table II, both values were determined in this study.

From Table I, it can be seen that in-plane E values are similar for all the panels with the exception of the double-tow 5HS woven composite (Panel A3). This suggests that for this general $\mathrm{SiC} / \mathrm{SiC}$ system, in-plane elastic modulus is not strongly dependent on 2D fiber architectures or on tensile loading direction. For in-plane UTS, the 2Dwoven 0/90 panels aligned in the primary fiber axes are of course the strongest since they were tested parallel to the fiber direction. Nevertheless, the braided panel with over three-quarters of the fibers oriented $23^{\circ}$ from the loading-axis, displayed a high in-plane UTS; whereas the $45 / 45$ panel displayed a relatively low UTS. But perhaps the most striking mechanical results were the high in-plane DFLS values for both the braided and $45 / 45$ panels.

These high DFLS results are confirmed in Figure 4 and Table II by the higher stress ranges over which $\mathrm{AE}$ was recorded for initiation of matrix cracking in the off-axis panels. In Figure 4, the AE activity versus applied CMC stress is plotted as normalized cumulative $\mathrm{AE}$ energy, which is the cumulative $\mathrm{AE}$ energy of each $\mathrm{AE}$ event up to a given event divided by the total $\mathrm{AE}$ energy of all the events. For the MI $\mathrm{SiC} / \mathrm{SiC}$ system, it has been shown [7] that this type of plot represents a good relative distribution of transverse or thru-thickness matrix cracking. In addition, multiplying the final matrix crack density, measured from polished sections after failure, by the normalized cumulative AE energy is a very good estimate of the actual stress-dependent matrix crack density versus applied CMC stress. The measured matrix crack densities at failure are shown in Table II and the estimated matrix crack density with stress in Figure 5. The difference in the shape of the matrix crack distribution between the double-tow and single-tow 2D woven composites is hypothesized to be due to the greater concentration and longer lengths of back-to-back $90^{\circ}$ minicomposites (see Discussion). Two different matrix crack distributions are evident for the two different off-axis loaded specimens. The 45/45 specimen has a very steep curve, whereas the braided specimens were similar in shape to the single-tow 2D composites. Neither off-axis composite appears to have reached matrix crack saturation since a decrease in the rate of $\mathrm{AE}$ activity was never 
achieved at higher stresses. It is also interesting to note that at a composite stress of 200 MPa (29 ksi), the off-axis tested braided specimens had little or no cracks; whereas the double-tow 2D woven composites had $\sim 5$ through-thickness matrix cracks (TTMC) per $\mathrm{mm}$.

For this study, several AE criteria were used to evaluate key stress levels near initiation of matrix cracking since these values typically represent upper design limits beyond which CMC moduli and axial thermal conductivity irreversibly decrease and the possibility exists for adverse environmental effects for $\mathrm{SiC} / \mathrm{SiC}$ composites [11]. These stress levels, which are indicated in Figure 6 and Table II, are associated with (1) the first AE event, (2) the first loud AE event which is defined as an AE event with an energy of at least one tenth the highest energy event not corresponding to failure, and (3) the effective $A E$ onset event which is determined by extrapolation of the high energy noise distribution down to the zero noise axis. It is evident in Table II that except for the first AE event, the other two stress measures for matrix cracking are significantly higher for the off-axis specimens than the on-axis specimens. Underlying mechanisms and technical significance for these stress levels will be discussed in the following sections.

\section{ANALYSIS AND DISCUSSION}

The effect of architecture and stress orientation on matrix cracking (or DFLS) and UTS are key properties that need to be understood for applications using $\mathrm{MI} \mathrm{SiC} / \mathrm{SiC}$ composites under multi-axial stress states. In the following sections, the results in Figures 2 and 4 and in Tables I and II will be mechanistically analyzed and compared to other data in the literature to better understand their scientific and technical significance.

\section{Matrix Cracking in 0/90 2D-Woven Composites Tested in $0^{\circ}$ Direction}

A variety of microscopic studies using on-axis tensile stresses on 2D-woven 0/90 $\mathrm{CMC}$ panels have shown that at lower stresses, initial transverse matrix cracks are usually either "tunnel" microcracks [12], which occur in the $90^{\circ}$ minicomposites ${ }^{*}$ oriented

\footnotetext{
* For the CMC of this study, a minicomposite consists of a single multi-fiber tow, the CVI BN interphase coating, and the initial CVI $\mathrm{SiC}$ matrix coating associated with tow.
} 
perpendicular to the $0^{\circ}$ loading-axis, and/or non-steady-state microcracks that are partially-bridged due to sufficient fiber-traction in the matrix crack wake to stop matrix crack propagation through-thickness. At higher stresses, these microcracks propagate through-thickness or link up with other microcracks to form TTMC over a range of stress levels.

AE methodologies have been successfully used to not only quantify but also to understand and model the occurrence and stress-strain effects of microcrack and TTMC behavior. Initial low energy events generally correspond to tunnel microcrack formation in $90^{\circ}$ minicomposites perpendicular to the stress direction. High energy events, those in the upper logarithmic decade of energy, correspond to either large microcracks and/or TTMC [13]. For 2D-woven 0/90 MI SiC/SiC panels tested in the $0^{\circ}$ direction, it has been demonstrated that the stress distribution for TTMC is controlled both by (1) the size distribution of $90^{\circ}$ minicomposites perpendicular to the load-bearing $0^{\circ}$ minicomposites, and (2) by the in-situ stress in the region of the composite outside of the load-bearing $0^{\circ}$ minicomposite, i.e., the portion of the composite composed of $90^{\circ}$ minicomposites and MI matrix [7, 14]. For panels fabricated from the random lay-up of standard single-tow woven fabric plies, the size distribution of $90^{\circ}$ minicomposites can crudely vary between the size of individual $90^{\circ}$ minicomposites to the size of two $90^{\circ}$ minicomposites that happen to be adjacent to one another. Whenever this back-to-back tow circumstance exists, the effective width of an unbridged tunnel crack would be approximately twice the crack width of a single minicomposite. This characteristic of back-to-back individual $90^{\circ}$ minicomposites is much more common in the double-tow woven $3.95 \mathrm{epcm}$ composite panel compared to single-tow woven panels. There are not only more regions of multiple $90^{\circ}$ minicomposites, but also the length of these regions (distance the tow is woven over four tows before it is woven under the fifth tow in the five-harness satin architecture) would be approximately twice the length of single-tow woven composites for the fiveharness satin weave since the epcm of the double-tow CMC was one-half that of the single-tow CMC. As a result, as shown in Figure 4, the double-tow woven panel displays the lowest onset stress and smallest stress distribution for TTMC in the on-axis panels.

In an effort to model architectural effects on the onset of through-thickness matrix cracking in $2 \mathrm{D}$-woven $0 / 90 \mathrm{SiC} / \mathrm{SiC}$ composites tested in the $0^{\circ}$ direction, a previous 
study [7] has examined the important microstructural factors affecting the internal stresses on the $90^{\circ}$ minicomposites since these appear to be the most critical flaws within the matrix that eventually cause TTMC. Two important factors were identified: (1) a built-in residual stress on the matrix and (2) the applied composite stress as modified by load shared by the $0^{\circ}$ minicomposites. As such, one can estimate the stress on the matrix region containing the 90 minicomposites (= minimatrix) by the following simple rule of mixtures relationship [7]:

$$
\sigma_{\min \text { imatrix }}=\frac{\left(\sigma_{c}+\sigma_{t h}\right)}{E_{c}}\left(\frac{E_{c}-f_{\min i} E_{\min i}}{1-f_{\min i}}\right)
$$

Here $\sigma_{c}$ is the applied composite stress, $\sigma_{\text {th }}$ is the residual stress in the matrix (Table I); $E_{c}$ is the measured composite elastic modulus from the $\sigma / \varepsilon$ curve (Table I); $f_{\text {mini }}$ is the volume fraction of the $0^{\circ}$ minicomposites in the loading direction (typically $\sim 2$ times the fiber content in the $0^{\circ}$ direction); and $E_{\operatorname{mini}}$ is the effective modulus of these $0^{\circ}$ minicomposites. Thus the stress on the 90 minicomposites can be reduced by increasing a compressive residual stress on the matrix and/or by increasing $f_{\operatorname{mini}}$. As shown in Table 1, one benefit of the $\mathrm{MI} \mathrm{SiC} / \mathrm{SiC}$ system is a compressive residual stress on the asfabricated matrix, but this stress did not vary much with the 2D architectures of this study. The exact source of this stress is not completely understood, but probably can be related to the silicon content in the matrix and the composite fabrication conditions. On the other hand, fiber content in the $0^{\circ}$ or primary fiber direction, $\mathrm{f}_{\text {primary }}$, can be increased to a large degree for the $\mathrm{MI} \mathrm{SiC/SiC} \mathrm{system} \mathrm{which} \mathrm{in} \mathrm{turn} \mathrm{should} \mathrm{increase} \mathrm{the} \mathrm{composite}$ stress for onset of TTMC. That this latter mechanism can indeed be utilized is seen in Fig. 7 which plots as open circles the AE onset cracking strength as function of $f_{\text {primary }}$ for the $0^{\circ}$-loaded $0 / 90 \mathrm{MI} \mathrm{SiC/SiC}$ composites of this study and a previous study [7].

\section{Matrix Cracking in 0/90 2D-Woven Composites Tested in $45^{\circ}$ Direction}

The stress-distribution for matrix cracking in the 45/45 off-axis Panel A4 differs considerably from those of 0/90 composites tested in an orthogonal direction. First AE events show that some small microcracks were formed at low stresses in the 45/45 composite (Table II), the source of which have not been determined for certain. There 
was considerable porosity in one thick matrix region between the outer two plies (Figure 8) which could have been one source. Most notably, there was also a very narrow stressdistribution for TTMC (Figure 4), which would correspond to a large population (high Weibull modulus) of flaws and/or microcracks that propagate through-thickness at and slightly above the matrix cracking stress. The important fact is that this composite (Panel A4) displayed a higher onset stress for TTMC than its theoretically equivalent 0/90 composite (Panel A1) loaded along its primary fiber axis. It is suggested that the higher matrix cracking stress and narrow stress-distribution for matrix cracking for this system is primarily due to a lack of minicomposites perpendicular to the direction of stress so that higher stresses are required for tunnel crack propagation. There is also the possibility that the 45/45 Panel A4 had a higher effective fraction of fibers carrying load in the testing direction, which in turn would have reduced internal matrix stresses on the tunnel cracks for a given applied composite stress.

\section{Matrix Cracking in 0/_67 2D-Braided Composite Tested in the Hoop Direction}

For the triaxially braided specimen, approximately $77 \%$ of the fibers, or a total fiber fraction of 0.26 , were oriented $23^{\circ}$ from the loading axis. This fraction is effectively higher than that of the 2D-woven composites loaded in the primary fiber direction, and thus appears to be one cause for the higher matrix cracking stress for the braided composite. As described above for the 0/90 composites, matrix cracks emanate from the region outside of the load-bearing minicomposites, e.g., from the minicomposites oriented $90^{\circ}$ to the loading axis. The same type of analysis can be applied here to the braided composites to determine if the stress ranges in the TTMC flaw-source regions (axial tow minicomposites, see Figure 1) of the matrix are similar to standard 2D-woven 0/90 composites oriented in one of the orthogonal directions.

Assuming the applicability of Eq. 1, there is a question as to how to approximate $E_{\min i}$ since the fibers are oriented at an angle to the loading axis. One limit would be to assume that the bias minicomposites would act as if they were in parallel, since there was the same fraction of minicomposites $+23^{\circ}$ as there are $-23^{\circ}$ from the tensile axis. The other extreme would be to assume that the modulus of a minicomposite at an angle to the 
loading axis would behave similar to a unidirectional ply oriented at an angle, and could therefore be estimated from laminate theory [15]:

$$
\frac{1}{E_{\theta}}=\frac{1}{E_{1}} \cos ^{4}(\theta)+\left(\frac{1}{G_{12}}-\frac{2 v_{12}}{E_{1}}\right) \sin ^{2}(\theta) \cos ^{2}(\theta)+\frac{1}{E_{2}} \sin ^{4}(\theta)
$$

where subscript 1 refers to the $0^{\circ}$ orientation of a minicomposite, subscript 2 refers to the transverse direction or $90^{\circ}$ orientation of a minicomposite, and $\theta$ refers to the orientation of the loading direction off the $0^{\circ}$ fiber axis. $G_{12}$ is the bulk modulus and $v_{12}$ is the Poisson's ratio.

To determine the effect of orientation, $\mathrm{E}_{\theta}$ was determined for the $23^{\circ}$ fiber orientation case relative to the value of $E_{1}\left(360 \mathrm{GPa}\right.$ for the braided composite $\left.{ }^{\#}\right) . \quad E_{2}$ is unknown for these minicomposites, but a conservative estimate would be $100 \mathrm{GPa}$, which would be on the low-end of elastic-moduli estimated for $90^{\circ}$ minicomposites in CVI SiC matrix composites [16]. $v_{12}$ was assumed to be 0.15 and $G_{12}$ was estimated from the simple isotropic relationship $\mathrm{E}_{1} / 2\left(1+v_{12}\right)$. Based on these simple assumptions $\mathrm{E}_{\theta} / \mathrm{E}_{1}=$ 0.943, a minor effect. Figure 9 shows the estimated matrix crack density versus minimatrix stress for both cases in comparison to the 2D composites. The "lower bound" assumes the minicomposites behave the same as parallel minicomposites and $E_{\min i}$ is determined from rule of mixtures based on the fractional content of fiber, $\mathrm{BN}$, and CVI $\mathrm{SiC}$. The "upper bound" refers to a reduced $E_{\min i}$ from Equation 2. There is only a small difference in minimatrix stress for the two extremes and they compare well with the composites loaded in the orthogonal direction. From this it would appear that matrix cracking in the braided composites is controlled by the stress acting on the axial minicomposites oriented perpendicular to the loading axis in the same manner as the 2Dwoven 0/90 composites with single tows. However, in order to increase fiber volume fraction, the $0 \pm 67$ braided composites were braided with two (double) tows woven together for both the axial and bias fibers. But there were a smaller fraction of minicomposites oriented perpendicular to the loading axis for the braided composites compared to the 2D-woven 0/90 composites. Also, the perpendicular minicomposites of

\footnotetext{
\# The fractional content of fiber, BN, and CVI SiC was $0.32,0.07$, and 0.25 , respectively. The fractional contents of the other composites were very similar to the data already reported in reference $7 . \mathrm{f}_{\min }$ for the bias fibers of the braided composites was 0.54 compared to $\sim 0.36$ for the orthogonal composites.
} 
the braided composites do not contact one another (Figure 10) and form back-to-back minicomposites as is the case for the $2 \mathrm{D}$-woven $0 / 90$ double tow composites. These two factors are probably the reason for the cracking behavior of the braided composite being more in line with that of the single tow woven composites and not the double tow woven composites. Figure 7 compares the effect of effective fiber fraction in the loading direction on $\mathrm{AE}$ onset stress for all the $\mathrm{MI} \mathrm{SiC/SiC} \mathrm{composites} \mathrm{studied} \mathrm{to} \mathrm{date} \mathrm{with} 2 \mathrm{D}$ woven and braided architectures and with minicomposites oriented perpendicular to the loading direction.

\section{Ultimate Strength for Off-Axis Panels}

The ultimate strengths of the panels loaded off-axis were generally less than those for panels tested in a primary fiber direction. This result is to be expected since the fibers were not aligned in the direction of applied stress and are subject to local bending and shear within a matrix crack. At this point, it is important to discuss the response of the different types of CMCs to off-axis loading.

CMC mechanical behavior has been defined as "matrix dominated" (Class III) and "fiber dominated" (Class II) [2, 17]. For matrix-dominated composites (e.g., SiC fiber-reinforced glass ceramic or $\mathrm{SiC}$ matrix composites), initial loads are shared by an uncracked matrix and the fibers. Therefore elastic properties are heavily influenced by the elastic properties of the matrix. Nonlinearity in the stress strain curve is caused by transverse matrix cracks (cracks perpendicular to the applied load) due to interface debonding and fiber sliding resulting in fiber pullout within the matrix crack and matrix crack opening. Transverse matrix cracking occurs for both on-axis and off-axis loading of composites.

For fiber-dominated composites (e.g., porous oxide/oxide, $\mathrm{C} / \mathrm{C}$, or $\mathrm{C} / \mathrm{SiC}$ composites), the matrix carries little load due to the fact that the matrix is porous or heavily microcracked, and the mechanical properties are controlled by the fiber (architecture) response to loading. When loaded on-axis, elastic moduli are typically only slightly larger than $\mathrm{f}\left(0^{\circ}\right) \times \mathrm{E}_{\mathrm{f}}$, and there is only minor nonlinearity to the stress strain curve since the matrix is highly porous and/or a high damage condition already exists in the matrix. When loaded in the off-axis, there is significant nonlinearity in stress strain 
behavior beginning near zero stress due to the absence of parallel fibers in the loading direction. More damage is created in the composite due to shear band formation, fiberrearrangement, inter-ply delamination, and fiber "scissoring". This results in high ultimate strains as long as the fibers can withstand the tensile and bending forces, but low ultimate strengths due to these combined forces on the fibers. This low off-axis UTS behavior for these fiber-dominated composites may be a limitation for certain applications.

The Sylramic-iBN composites are an excellent example of matrix-dominated composites and how off-axis properties can be maximized which may be important for future applications. To demonstrate this, the ultimate tensile strength data from the composites tested in this study (see Table I) can be compared to UTS data in the literature for a variety of fiber-dominated and matrix-dominated 2D-woven, braided, and crossplied ceramic and polymer composites that were tested in a primary fiber direction as well as in an off-axis direction. Descriptions of these composites and their ultimate properties are listed in Table III for 0/90 composites tested in the 0 and 45/45 direction and in Table IV for 0/90 and braided composites tested at multiple angles. These composites included 2D plain-woven carbon fiber reinforced epoxy [18], 2D triaxially braided carbon fiber reinforced epoxy [19], 2D eight-harness satin woven $\mathrm{Al}_{2} \mathrm{O}_{3}$-fiber reinforced porous oxide matrix (mullite) composites [20], Nicalon (Nippon Carbon, Japan) fiber reinforced carbon matrix [2, 21], Nicalon fiber reinforced glass matrix composites [2,22], Nicalon fiber reinforced CVI SiC matrix composites [2, 21], carbon fiber reinforced carbon matrix composites [17, 21], and 2D five-harness satin woven HiNicalon (Nippon Carbon, Japan) and Sylramic fiber reinforced MI composites [23].

It is difficult to compare all of the off-axis UTS data on an absolute basis since composites vary considerably in fiber volume fractions, in-situ strength properties of the fibers, interfacial sliding stress, and fiber bending stiffness, which is dependent on fiber modulus and diameter. However, when comparing the 45/45-direction UTS of 0/90 composites, the matrix-dominated $\mathrm{SiC}$ composites, whether reinforced by Nicalon, HiNicalon, Sylramic, or Sylramic-iBN SiC fibers (see Tables I and III), exhibited the best off-axis UTS values (158 to $242 \mathrm{MPa}$ ) compared to the fiber-dominated composites (all < $100 \mathrm{MPa}$ ) regardless of fiber-type. 
To crudely estimate the general effect of composite-type and off-axis testing direction on effective fiber strength or load-carrying ability, one can eliminate the fiber tensile strength and volume fraction effects from the strength data by normalizing the offaxis UTS data of Tables I, III, and IV using the following relationship:

Normalized Effective Fiber Strength $=\left(\sigma_{\text {ult off-axis }} / \sigma_{\text {ult } 0}\right)\left(f_{0} / \mathrm{f}{ }_{\text {off-axis }}\right)$

where $\sigma_{\text {ult } 0}$ and $\mathrm{f}_{0}$ refers, respectively, to the UTS and fraction of fibers in the primary fiber direction; and $\sigma_{\text {ult off-axis }}$ and $\mathrm{f}^{*}$ off-axis refers, respectively, to the UTS and effective load-bearing fraction of fibers in the off-axis direction. It can be assumed for $0 / 90$ composites when loaded symmetric to the primary fiber directions, e.g., $45 / 45$, that both fiber axes are carrying load, so that $\mathrm{f}^{*}$ off-axis $=2 \mathrm{f}_{0}$. For non-symmetric loading, it can be assumed that the fibers in the axis at the greatest angle to the loading direction will fracture first, debond, and/or pull apart, leaving the other primary axis fibers to control UTS, so that $\mathrm{f}^{*}{ }_{\text {off-axis }}$ equals $\mathrm{f}_{0}$ of the remaining fibers. For braided composites, specimens tested in the hoop direction were compared to specimens from the same panel tested in the axial direction (C/epoxy - Table IV) or to $0 / 90$ specimens tested in the 0 direction (Syl-iBN MI - Table I).

Based on these assumptions and Eq. 3, Fig. 11 shows the normalized fiber strength results as a function of test angle using the UTS data from Tables I, III, and IV. Again the four high-modulus SiC-based matrix composites exhibit the best relative retention of fiber strength. For the fiber-dominated or low-modulus matrix composites, C/epoxy, $\mathrm{Al}_{2} \mathrm{O}_{3} /$ mullite, $\mathrm{Nic} / \mathrm{C}, \mathrm{C} / \mathrm{C}$, and $\mathrm{C} / \mathrm{SiC}$, there was excellent correlation at $45^{\circ}$, but poorer off-axis strengths. The two matrix-dominated glass-ceramic matrix composites were in between the fiber-dominated and SiC-based matrix-dominated composites probably due to the lower modulus of the glass-ceramic matrix compared to $\mathrm{CVI}$ and MI SiC matrices. It is significant that the braided and $0 / 90^{\circ} \mathrm{C} /$ epoxy data from

\footnotetext{
* Note that in Equation 3, the ellipsoid character of off-axis oriented fibers in the plane of failure was not taken into account. A more exhaustive and complicated analysis would require not only the angle, but the nature of fiber/matrix sliding which is not well understood [2], the matrix crack opening and the degree of fiber straightening. From an engineering and design standpoint, the simple analysis performed here is considered to be more straightforward and useful.
} 
different studies over the range of angles tested correlate with one another, justifying some of the crude assumptions made above.

For fiber orientations 25 to $45^{\circ}$ off the loading axis, the relative stress-carrying ability of the Syl-iBN fibers in high-modulus SiC-based matrices ranged from $50 \%$ to $30 \%$ of the fiber strength, respectively, when oriented in the primary $0^{\circ}$ direction. Though the relative stress-carrying ability decreased with angle, it was still far superior to the fiber-dominated systems (50\% greater relative stress at $25^{\circ}$ and $100 \%$ greater relative stress at $45^{\circ}$ ). This is an important design consideration for composite and architecture selection when appreciable off-axis loading applications are pursued.

Note that the Nic/CVI SiC [2, 21] composites had the highest relative off-axis strength. As discussed above, the Eq. 3 analysis does not account for such material properties as interfacial sliding stress and fiber bending stiffness, which will affect the mechanics of fiber fracture when aligned at an angle within a transverse matrix crack. The absolute off-axis strengths of the $\mathrm{NiC} / \mathrm{CVI} \mathrm{SiC}$ composites were similar to the HN/MI and Sylramic/MI and less than the Syl-iBN / MI composites. Also, $\sigma_{\text {ulto }}$ of the Nic/CVI SiC composites were poor indicating a low in-situ (after processing) fiber strength in comparison to the other $\mathrm{SiC} / \mathrm{SiC}$ composites, possibly resulting in higher than expected normalized fiber strength results. Another possibility is that the beneficial effects of a lower fiber modulus and interfacial sliding stress are becoming evident for the Nicalon composites. Nevertheless, it is suggested that the two lines in Figure 11 represent, albeit crudely, off-axis UTS for matrix-dominated and fiber-dominated CMC. These relationships can be used by designers as a "rule-of-thumb" when considering the type of composite and fiber architecture to be used in a component with off-axis stresses.

\section{Implications for Architecture Design of MI SiC/SiC Components}

From the observations of this study, one can summarize several constituent and architectural guidelines that can be applied to future designs of components fabricated with ceramic composites in general and non-oxide Syl-iBN MI SiC/SiC composites in particular where high off-axis strengths are required. It is assumed that the design goals will be to achieve as high a matrix cracking stress as possible as well as a high ultimate tensile strength along the principal stress directions within the components. 
First, the matrix constituent should display a high stiffness and high strain capability by utilizing a high-modulus composition, such as $\mathrm{SiC}$, and a fabrication approach that results in as low porosity as possible, such as $\mathrm{MI} \mathrm{SiC}$. For the $\mathrm{SiC} / \mathrm{SiC}$ composites of this study, the high-modulus low-porosity MI matrix allows the composite elastic modulus to be fairly independent of architecture and in-plane testing direction. Furthermore, as is the case with the MI process, the composite fabrication process should (if possible) result in a residual compressive stress on the matrix critical flaws after final composite fabrication (see Table I). In contrast to residual stresses caused by thermal expansion mismatch between the fiber and matrix, the residual stress of the MI process appears to be independent of temperature up to at least $815^{\circ} \mathrm{C}$ [24].

Second, the fiber constituent should be as strong as possible in its as-produced condition and retain a high fraction of this strength after composite fabrication. The onaxis UTS values for the Sylramic-iBN composites of this study (see Table 1) and other studies [7] when normalized by the fiber volume fraction are the highest ( 2400 MPa) displayed to date by any woven SiC-based fiber. For off-axis UTS, high fiber strength is also important for obtaining high fiber load-carrying ability during bending within matrix cracks. In addition, the fiber should have as high a modulus as possible in order to shift composite loads away from the matrix flaws and onto the fiber and reduce matrix crack opening. Also in combination with the interphase coating, the fiber surface conditions should be such as to provide high interfacial shear to inhibit large crack-bridging fiber lengths that will both statistically reduce fiber strength within the cracks (gauge length effect) and allow more fiber bending for off-axis loading. Due to the relatively high surface roughness of the Sylramic-iBN fiber and the stiffness of the combined iBN/BN interphase coating, interfacial shear strengths in Sylramic-iBN/BN/SiC systems are approximately $70 \mathrm{MPa}$, much higher than observed with other smoother fiber types and/or carbon interfacial coatings when processed in the same manner.

Third, the geometry and orientation of the fiber architecture must be judiciously selected in relation to the directions and magnitudes of the principal stresses within the CMC component. A primary guideline shown in this study is to achieve effective fiber volume fractions as a high as possible in these principal stress directions, both to reduce stress on matrix flaws and to increase the stress and strain for ultimate failure. However, 
as shown here, the conventional approach of putting the primary fiber axes directly along the principal stress directions may not be required and perhaps should be avoided. For example for the $0 / 90$ panel aligned at $45^{\circ}$ to the primary fiber axes, the $\mathrm{AE}$ onset cracking stress increased from 190 to $220 \mathrm{MPa}$ due in part to removal of minicomposites being perpendicular to the loading direction. But UTS values decreased significantly from 410 to $242 \mathrm{MPa}$ because of fiber strength loss within open matrix cracks. However, for the braided panel aligned at a smaller $23^{\circ}$ to the primary fiber axes, onset stresses remained high at $\sim 220 \mathrm{MPa}$ and UTS only degraded to $\sim 350 \mathrm{MPa}$. Generally it is thought that high UTS values are desirable for composite materials; but for non-oxide ceramic composites, such as $\mathrm{MI} \mathrm{SiC/SiC,} \mathrm{structural} \mathrm{life} \mathrm{degrades} \mathrm{in} \mathrm{a} \mathrm{complex} \mathrm{manner} \mathrm{above} \mathrm{the}$ cracking stress due to environment ingress through the open matrix cracks. In addition, above the cracking stress, composite properties such as modulus and thermal conductivity also degrade in complex and unpredictable ways. Thus today most CMC designers of non-oxide $\mathrm{CMC}$ components that require long service life find it more desirable to achieve as high a cracking stress as possible in the principal stress directions, but still retain some comfortable level of ultimate strength. As shown in this study, this goal can best be achieved by increasing the effective fiber fraction in these directions, but in doing so, one should attempt to minimize the size and volume fraction of minicomposites oriented perpendicular to these directions. For those cases where perpendicular minicomposites cannot be avoided, this and other studies [7, 25] have shown that the fairly robust mechanistic-based mini-matrix approach can be helpful in understanding and modeling matrix cracking for a variety of 2D and 3D fiber architectures.

\section{SUMMARY AND CONCLUSIONS}

A 2D-woven 0/90 and a 2D-braided -67/0/67 Sylramic-iBN reinforced meltinfiltrated $\mathrm{SiC}$ matrix panel when tensile tested in-plane at an angle symmetrically located between the two primary fiber directions were both shown to exhibit high stress for the onset of through-thickness matrix cracking. The matrix cracking and deflection from linearity stresses were actually higher for the off-axis loading condition compared to 2D-woven $0 / 90$ panels loaded in one of the primary fiber directions. For both panels, this improved cracking behavior can be explained in part by a higher effective fraction of 
fibers in the loading direction which reduces internal stress on critical matrix flaws for a given composite stress. For the woven panel, there also existed an absence of weak minicomposites oriented perpendicular to the loading direction. For the braided panel, which did have a low fraction of axial minicomposites loaded perpendicular to the loading direction, the minicomposites were well separated from one another which prohibited the occurrence of "back-to-back" $90^{\circ}$ minicomposites that are the source of low strength matrix cracks in $2 \mathrm{D}$-woven $0 / 90$ composites with similar tow size. Acoustic emission measurements on the braided panel also showed that that the onset stress for through-thickness matrix cracking and the cracking distribution with increasing stress behaved effectively the same as $2 \mathrm{D}$-woven $0 / 90$ composites when loaded in a primary fiber direction. Not only does this confirm that the weak minicomposites perpendicular to the loading direction are the critical source of through-thickness matrix cracks, it should also enable use of the "minimatrix" approach [7] to model and improve matrix cracking and DFL stresses of CMC components with braided and other architectures.

In terms of in-plane ultimate tensile strength, the Syl-iBN/MI SiC composites were found to be superior in both on-axis and off-axis behavior in comparison to other 2D ceramic composites in the literature with either fiber-dominated or matrix-dominated mechanical behavior. The off-axis behavior can be attributed primarily to the relatively high modulus and strength of the MI matrix which carries significant load and to the high strength of the Sylramic-iBN fiber that is retained during composite processing.

\section{ACKNOWLEDGEMENT}

We would like to thank Wayne Steffier of Hyper-Therm Composites Incorporated for provision of the excellent property database of the various CMCs that they fabricate.

\section{REFERENCES}

1. J. Aveston, G.A. Cooper, and A. Kelly, "Single and Multiple Fracture," Proceedings of the The Properties of Fibre Composites Conference, IPC Science and Tech. Press, Ltd., Guildford, Surrey, England, pp. 15-24 (1971)

2. C. Cady, F. E. Heredia, and A.G. Evans, "In-Plane Mechanical Properties of Several Ceramic-Matrix Composites,” J. Am. Ceram. Soc., 78 [8] 2065-78 (1995) 
3. E.A.V. Carelli, H. Fujita, J.Y. Yang, and F.W. Zok, "Effects of Thermal Aging on the Mechanical Properties of a Porous-Matrix Ceramic Composite,” J. Am. Ceram. Soc., 85 [3] 595-602 (2002).

4. J.A. DiCarlo, H-M. Yun, G.N. Morscher, and R.T. Bhatt, "SiC/SiC Composites for $1200^{\circ} \mathrm{C}$ and Above" Handbook of Ceramics Composites, ed. N. Bansal, Chapter 4; pp. 77-98 (Kluwer Academic; NY, NY: 2005)

5. H.M. Yun, J.Z. Gyekenyesi, Y.L. Chen, D.R. Wheeler, and J.A. DiCarlo, "Tensile behavior of $\mathrm{SiC} / \mathrm{SiC}$ composites reinforced by treated Sylramic $\mathrm{SiC}$ fibers." Ceram. Eng. Sci. Proc., 22, pp. 521-531 (2001).

6. G.N. Morscher, "Modal Acoustic Emission of Damage Accumulation in a Woven SiC/SiC Composite," Comp. Sci. Tech. 59 687-697 (1999).

7. G.N. Morscher, "Stress-Dependent Matrix Cracking in 2D Woven SiC-fiber Reinforced Melt-Infiltrated SiC Matrix Composites”, Comp. Sci. Tech., 64 pp. 1311-1319 (2004)

8. ASTM C-1275, "Standard Test Method for Monotonic Tensile Behavior of Continuous Fiber-Reinforced Advanced Ceramics with Solid Rectangular CrossSection Test Specimens at Ambient Temperature,” ASTM, 100 Barr Harbor Drive, West Conshohocken, PA (2000)

9. S.Kalluri, A. Calomino, and D.N. Brewer, "An Assessment of Variability in the Average Tensile Properties of a Melt-Infiltrated SiC/SiC Composite," Cer. Eng. Sci. Proc., 25 [4] 79-86 (2004)

10. G.N. Morscher and V. Pujar, "Melt-Infiltrated SiC Composites for Gas Turbine Engine Applications," Proceedings of ASME Turbo Expo 2004: Power for Land, Sea, and Air, June 14-17, 2004, Vienna, Austria paper no. GT2004-54233

11. G.N. Morscher and J.D. Cawley, "Intermediate Temperature Strength Degradation in SiC/SiC Composites," J. European Ceramic Society, vol. 22, no. 14-15, pp. 2777-2788 (2002)

12. B.N. Cox and D.B. Marshall, "Crack Initiation in Fiber-Reinforced Brittle Laminates," J. Am. Ceram. Soc., 79 [5] 1181-88 (1996)

13. G.N. Morscher, "Modal Acoustic Emission Source Determination in Silicon Carbide Matrix Composites," in Review of Progress in Quantitative 
Nondestructive Evaluation, eds. D.O. Thompson and D.E. Chimenti, CP 509, American Institute of Phisics, pp. 383-390 (2000)

14. G.N. Morscher, "Matrix Cracking in Four Different 2D SiC/SiC Composite Systems", Published in the 35th International SAMPE Technical Conference Proceedings (CD), Dayton, OH (2003)

15. R.M. Jones, Mechanics of Composite Materials (Hemisphere Publishing Corp., NY: 1975) p. 54

16. G.N. Morscher, "Modeling the Elastic modulus of 2D Woven CVI SiC Composites”, Comp. Sci. Int., 66 [15] 2804-2814 (2006).

17. F.W. Zok, "Fracture Analysis of Fiber-Reinforced Ceramic Composites," ASM Engineered Materials Handbook Vol. 21: Composites pp. 407-418 (2001)

18. N.K. Naik, P.S. Shemekar, and M.V. Hosur, "Failure Behavior of Woven Fabric Composites," J. Comp. Tech. and Res., vol 13, no. 2 pp 107-16 (1991)

19. P.J. Falzon and I. Herzberg, "Mechanical performance of 2-D braided carbon/epoxy composites", Comp. Sci. Tech., 58, 253-265 (1998)

20. J.A. Heathcote, X.Y. Gong, J. Yang, U. Ramamurty, and F.W. Zok, "In-Plane Mechanical Properties of an All-Oxide Ceramic Composite," J. Am. Ceram. Soc., 82 [10] 2721-2730 (1999)

21. Wayne Steffier, Composite Data Sheets, Hyper-Therm Composites, Inc. (2006)

22. C.S. Lynch and A.G. Evans, "Effects of Off-Axis Loading on the Tensile Behavior of a Ceramic-Matrix Composite" J. Am. Ceram. Soc., 79 [12] 3113-23 (1996)

23. Unpublished data from NASA's Enabling Propulsion Materials Program.

24. G.N. Morscher, Unpublished research based on unload-reload tests performed at $815^{\circ} \mathrm{C}$

25. G.N. Morscher, H.M. Yun, J.A. DiCarlo, "Matrix Cracking in 3D Orthogonal Melt-Infiltrated $\mathrm{SiC} / \mathrm{SiC}$ Composites with Various Z-Fiber Types", J. Am. Ceram. Soc., 88 [1] 146-153 (2005) 
Table I: Composite Properties

\begin{tabular}{|c|c|c|c|c|c|c|c|}
\hline Panel & 2D Architecture & $\begin{array}{c}\text { Thick- } \\
\text { ness, } \\
\mathrm{mm}\end{array}$ & $\begin{array}{c}\text { Total } \\
\text { Fiber } \\
\text { Fraction } \\
\mathrm{f}\end{array}$ & $\begin{array}{c}\text { Test } \\
\text { Angle to } \\
\text { Primary } \\
\text { Fibers }\end{array}$ & $\begin{array}{c}\mathrm{E}, \\
\text { GPa }\end{array}$ & $\begin{array}{c}\text { UTS, } \\
\text { MPa }\end{array}$ & $\begin{array}{c}\text { Residual } \\
\text { Stress in } \\
\text { Matrix, } \\
\text { MPa }\end{array}$ \\
\hline A1 & $\begin{array}{c}8.7 \text { epcm 0/90,8 ply, } \\
\text { 5HS, single-tow }\end{array}$ & 2.3 & 0.39 & $0^{\circ}$ & 261 & 410 & -60 \\
\hline A2 & $\begin{array}{c}7.9 \text { epcm 0/90, 8 ply, } \\
\text { 5HS, single-tow }\end{array}$ & 2.0 & 0.39 & $0^{\circ}$ & 250 & 463 & -50 \\
\hline A3 & $\begin{array}{c}3.95 \text { epcm (2) epi 0/90, } \\
8 \text { ply, 5HS, double-tow }\end{array}$ & 2.1 & 0.39 & $0^{\circ}$ & 202 & 444 & -50 \\
\hline A4 & $\begin{array}{c}8.7 \text { epcm 45/45,8 ply, } \\
\text { 5HS, single-tow }\end{array}$ & 2.4 & 0.36 & $45^{\circ}$ & 233 & 242 & -40 \\
\hline B1 & $\begin{array}{c}\text { 0/_67 Braid, 4 layer, } \\
\text { tri-axial braid, double- } \\
\text { tow }\end{array}$ & 1.8 & $0.32^{*}$ & $23^{\circ}$ & 240 & 338 & -60 \\
\hline
\end{tabular}

* Fraction of fibers in the axial direction $=0.06$;

Fraction of fibers in each of the bias directions $=0.13$

Table II: Matrix Cracking Properties

\begin{tabular}{|c|c|c|c|c|c|c|c|}
\hline Panel & $\begin{array}{c}\text { DFLS, } \\
.002 \% \\
\text { Offset, } \\
\mathrm{MPa}\end{array}$ & $\begin{array}{c}\text { DFLS, } \\
.005 \% \\
\text { Offset, } \\
\mathrm{MPa}\end{array}$ & $\begin{array}{c}1 \text { st AE } \\
\text { Stress, } \\
\mathrm{MPa}\end{array}$ & $\begin{array}{c}1 \text { st } \\
\text { Loud } \\
\text { AE } \\
\text { Stress, } \\
\mathrm{MPa}\end{array}$ & $\begin{array}{c}\mathrm{AE} \\
\text { Onset } \\
\text { Stress, } \\
\mathrm{MPa}\end{array}$ & $\begin{array}{c}\text { No. of Loud } \\
\text { Ovents prior to } \\
\text { AE Onset } \\
\text { Stress - Tot \# } \\
\text { Loud Events }\end{array}$ & $\begin{array}{c}\text { Final } \\
\text { Matrix } \\
\text { Crack } \\
\text { Density, } \\
\# / \mathrm{mm}\end{array}$ \\
\hline A1 & 147 & 174 & 132 & 170 & 190 & $4-141$ & -- \\
\hline A2 & 130 & 173 & 100 & 159 & 182 & $1-141$ & 10.3 \\
\hline A3 & 135 & 176 & 128 & 138 & 157 & $2-134$ & 9.0 \\
\hline \multicolumn{7}{|c|}{ Off-Axis Oriented Composites } \\
\hline A4 & 210 & 225 & 56 & 197 & 220 & $1-65$ & 4.0 \\
\hline B1 & 232 & 259 & 83 & 187 & 215 & $2-95$ & 4.9 \\
\cline { 2 - 8 } & 195 & 231 & 135 & 193 & 210 & $3-134$ & -- \\
\hline
\end{tabular}


Table III: Ultimate Strength Properties of 0/90 Composites in Literature Tested in Orthogonal and 45/45 Orientations

\begin{tabular}{|c|c|c|c|c|c|c|c|}
\hline Composite & Fiber Architecture & Ref & $\mathrm{f}=2 \mathrm{f}_{0}$ & $\begin{array}{l}\mathrm{E}(0), \\
\mathrm{GPa}\end{array}$ & $\begin{array}{l}\text { UTS(0), } \\
\mathrm{MPa}\end{array}$ & $\begin{array}{l}\text { E(45) } \\
\mathrm{GPa}\end{array}$ & $\begin{array}{l}\text { UTS(45), } \\
\mathrm{GPa}\end{array}$ \\
\hline \multicolumn{8}{|c|}{ Matrix Dominated Composites } \\
\hline Sylramic-MI & $5 \mathrm{HS}$ & 21 & 0.34 & 268 & 344 & 258 & 200 \\
\hline Hi-Nic-MI & $5 \mathrm{HS}$ & 21 & 0.34 & 210 & 351 & 169 & 158 \\
\hline Nic-CVI SiC & Plain Weave & 2 & $\sim 0.4$ & 265 & 255 & NA & 210 \\
\hline Nic-CVI SiC & $8 \mathrm{HS}$ & 21 & 0.36 & 240 & 248 & 183 & 192 \\
\hline NiC-CAS & 0/90 laminate & 2 & $\sim 0.4$ & 136 & 215 & NA & 95 \\
\hline \multicolumn{8}{|c|}{ Fiber Dominated Composites } \\
\hline Nic -C [2] & --------- & 2 & $\sim 0.4$ & 60 & 320 & NA & 80 \\
\hline Nic-C [21] & $8 \mathrm{HS}$ & 21 & 0.36 & 70 & 252 & 34 & 76 \\
\hline C-CVI SiC [21] & $8 \mathrm{HS}$ & 21 & 0.36 & 87 & 324 & 62 & 74 \\
\hline $\mathrm{C}-\mathrm{C}[21]$ & $8 \mathrm{HS}$ & 21 & 0.36 & 101 & 305 & 21 & 70 \\
\hline Al2O3/Mullite & $8 \mathrm{HS}$ & 20 & $\sim 0.4$ & $\sim 97$ & 210 & 50 & 52 \\
\hline
\end{tabular}

Table IV: Ultimate Strength Properties of Composites in Literature Tested in Multiple Directions

\begin{tabular}{|c|c|c|c|c|c|c|}
\hline Composite & Fiber Architecture & Ref & $\begin{array}{l}\text { Orien } \\
\text { tation }\end{array}$ & $\begin{array}{l}\mathrm{f}_{0} \text { or } \\
\mathrm{f}_{\text {off-axis }}^{*}\end{array}$ & $\begin{array}{l}\mathrm{E}, \\
\mathrm{GPa}\end{array}$ & $\begin{array}{l}\text { UTS, } \\
\mathrm{MPa}\end{array}$ \\
\hline \multicolumn{7}{|c|}{ Matrix Dominated Composites } \\
\hline \multirow{3}{*}{ Nic-MAS } & 0/90 laminate & 22 & 0 & 0.185 & 130 & 385 \\
\hline & & & 30 & 0.185 & 120 & 147 \\
\hline & & & 45 & 0.37 & 110 & 157 \\
\hline \multicolumn{7}{|c|}{ Fiber Dominated Composites } \\
\hline & & & & & & \\
\hline \multirow[t]{4}{*}{$\mathrm{C}$ - epoxy PW } & Plain Weave & 18 & 0 & 0.25 & NA & 461 \\
\hline & & & 15 & 0.25 & NA & 274 \\
\hline & & & 30 & 0.25 & NA & 143 \\
\hline & & & 45 & 0.5 & NA & 127 \\
\hline \multirow[t]{4}{*}{$\mathrm{C}$ - epoxy braid } & $0 / \pm 45$ Axial & 19 & 0 & 0.15 & 40.8 & 417 \\
\hline & $0 / \pm 60$ Axial & & 0 & 0.11 & 31.6 & 318 \\
\hline & $0 / \pm 60$ Ноop & & 30 & 0.46 & 49.9 & 400 \\
\hline & $0 / \pm 45$ Ноор & & 45 & 0.42 & 19.8 & 165 \\
\hline
\end{tabular}




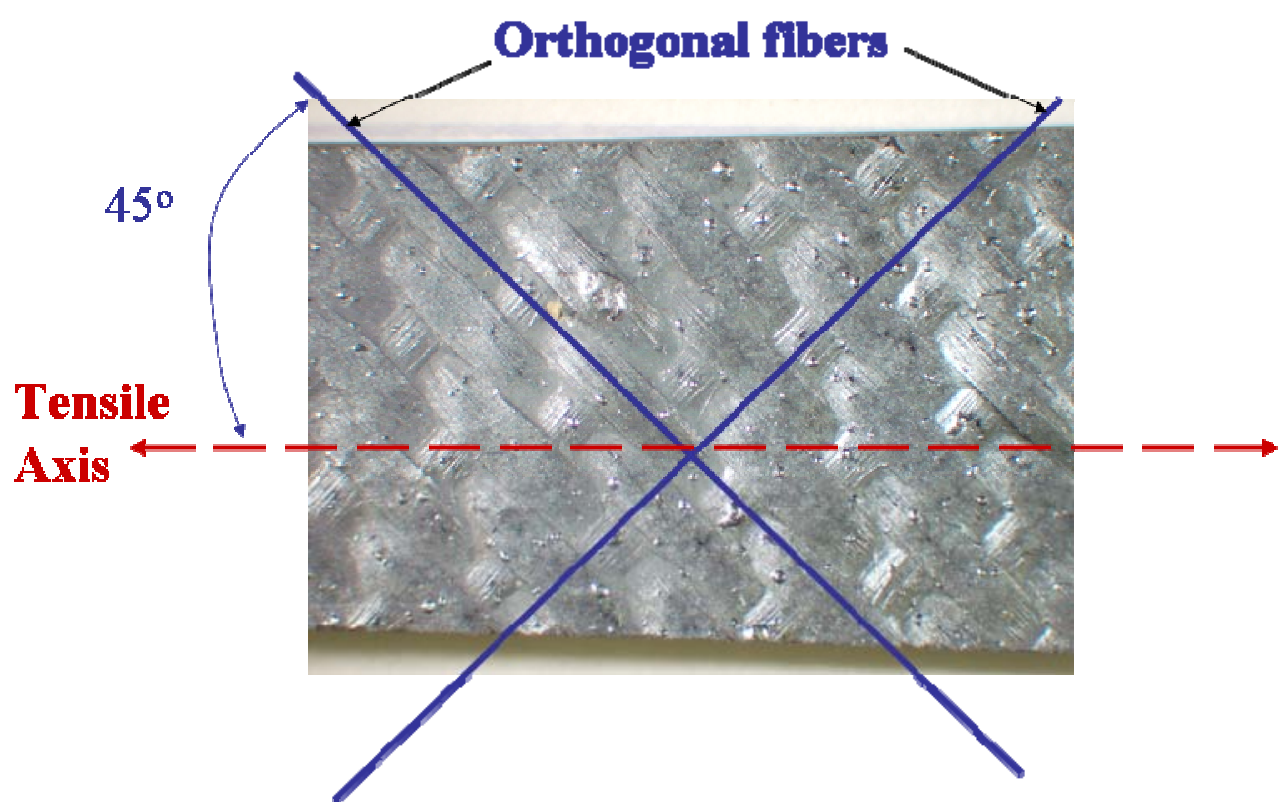

(a)

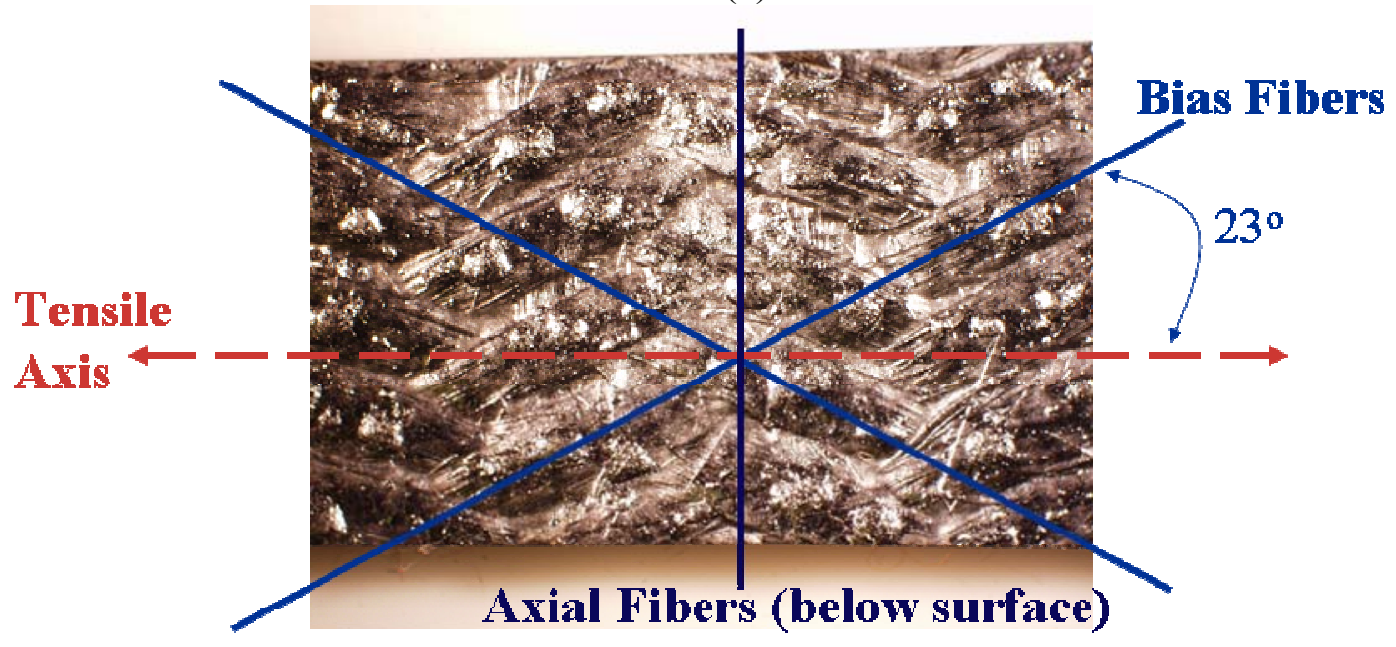

(b)

Figure 1. Photographs of composite surface showing fiber orientations and tensile axis for (a) 45/45 panel A4 and (b) $0 \pm 67$ braid panel B1. 


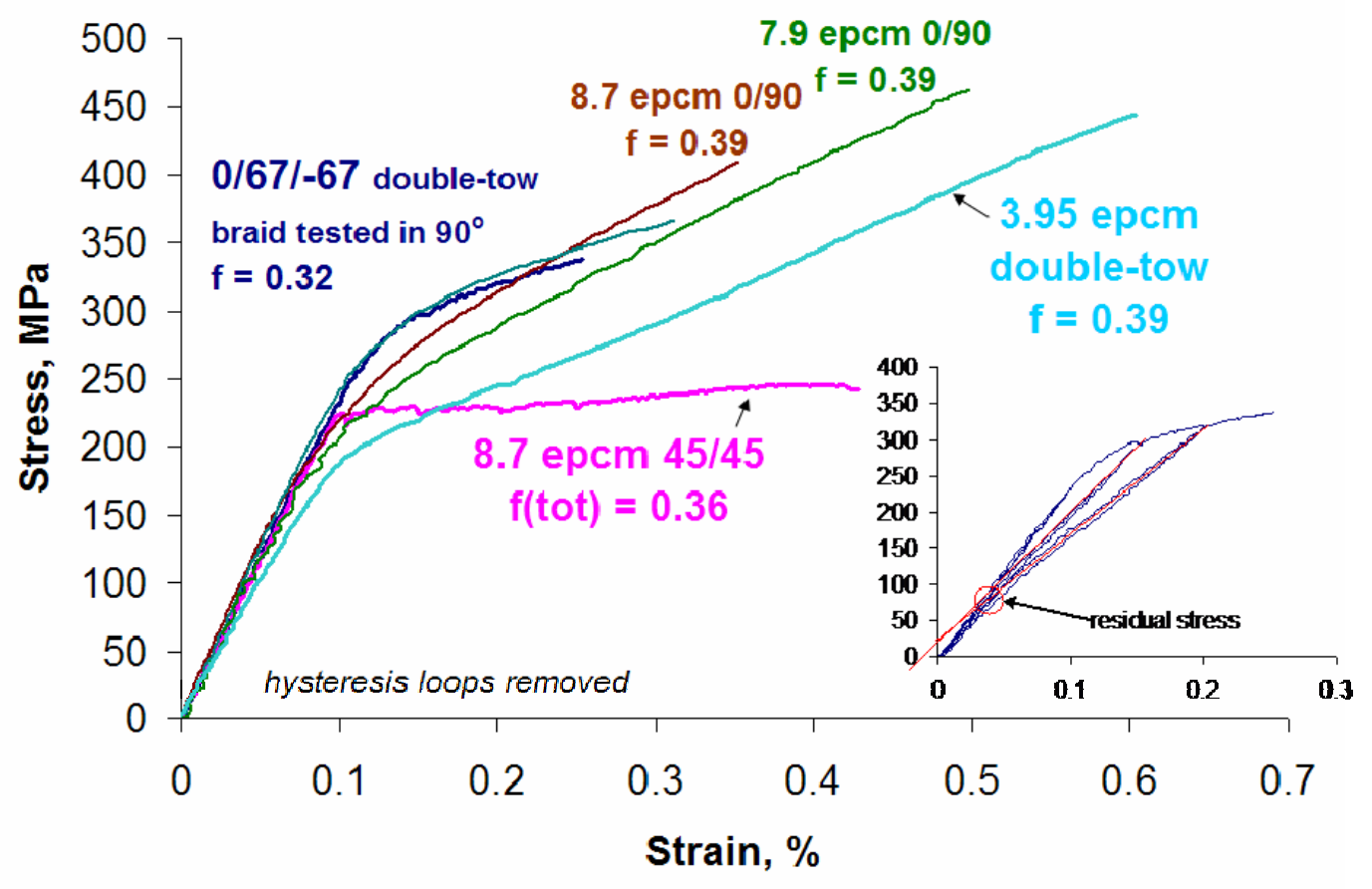

Figure 2: Stress-strain curves of off-axis and orthogonally aligned composites with the hysteresis loop removed for clarity. An example of the hysteresis loops for $0 / \pm 67$ Braid (1) is shown in the inset. 


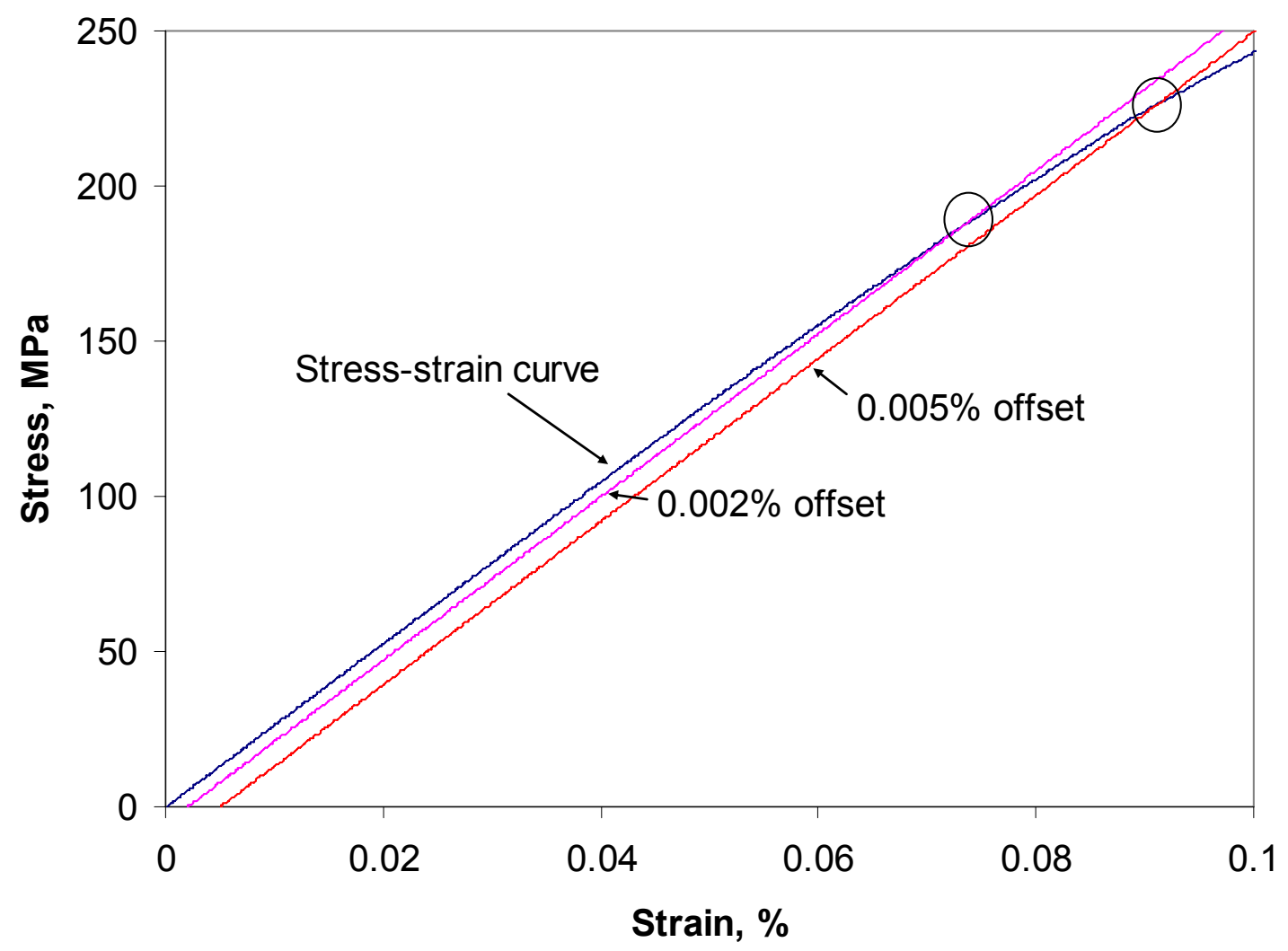

Figure 3: DFL-stress construction for a braided specimen. Note, only the low strain portion of the stress-strain curve is plotted. 


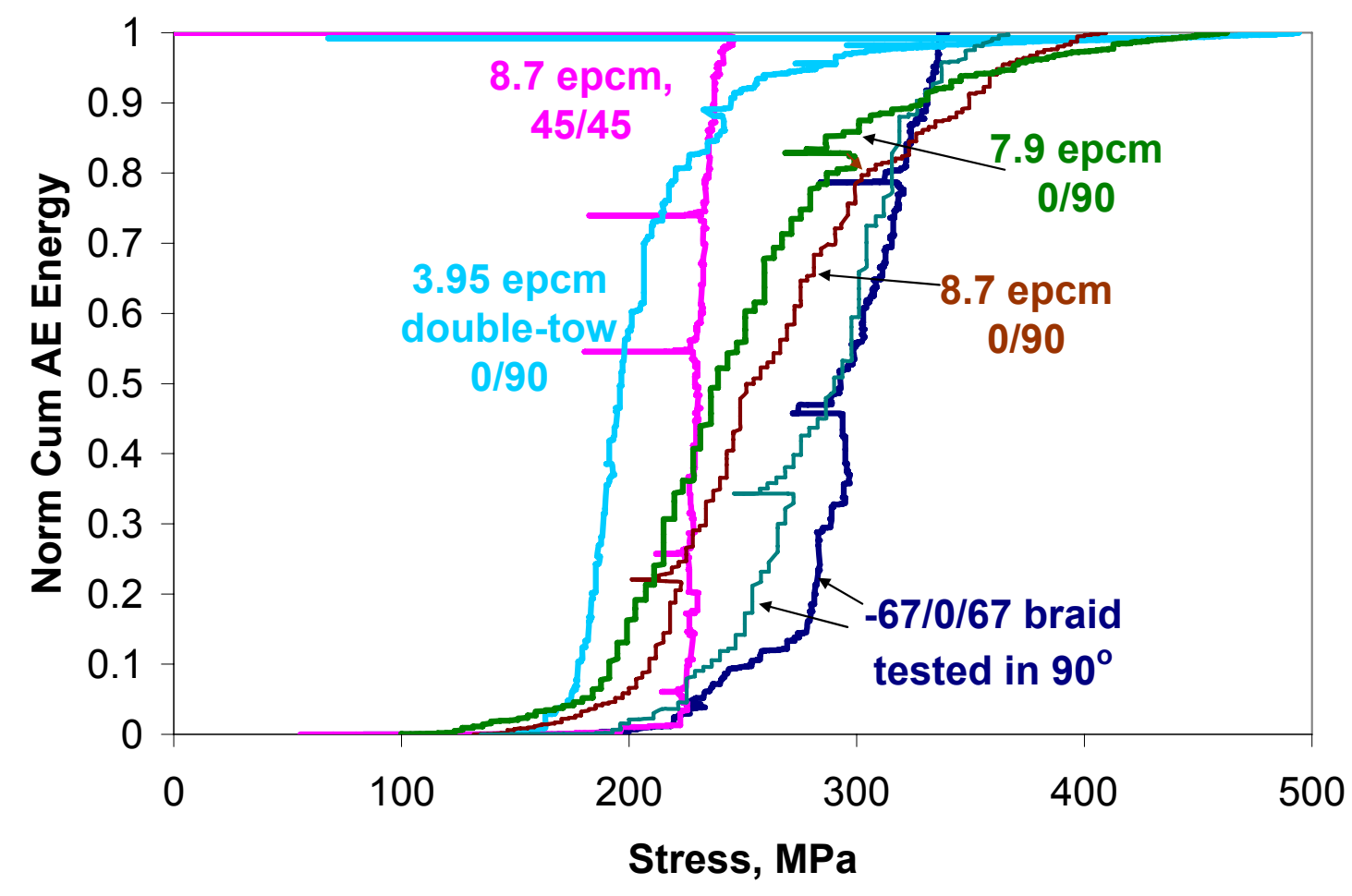

Figure 4. AE activity versus composite stress. 


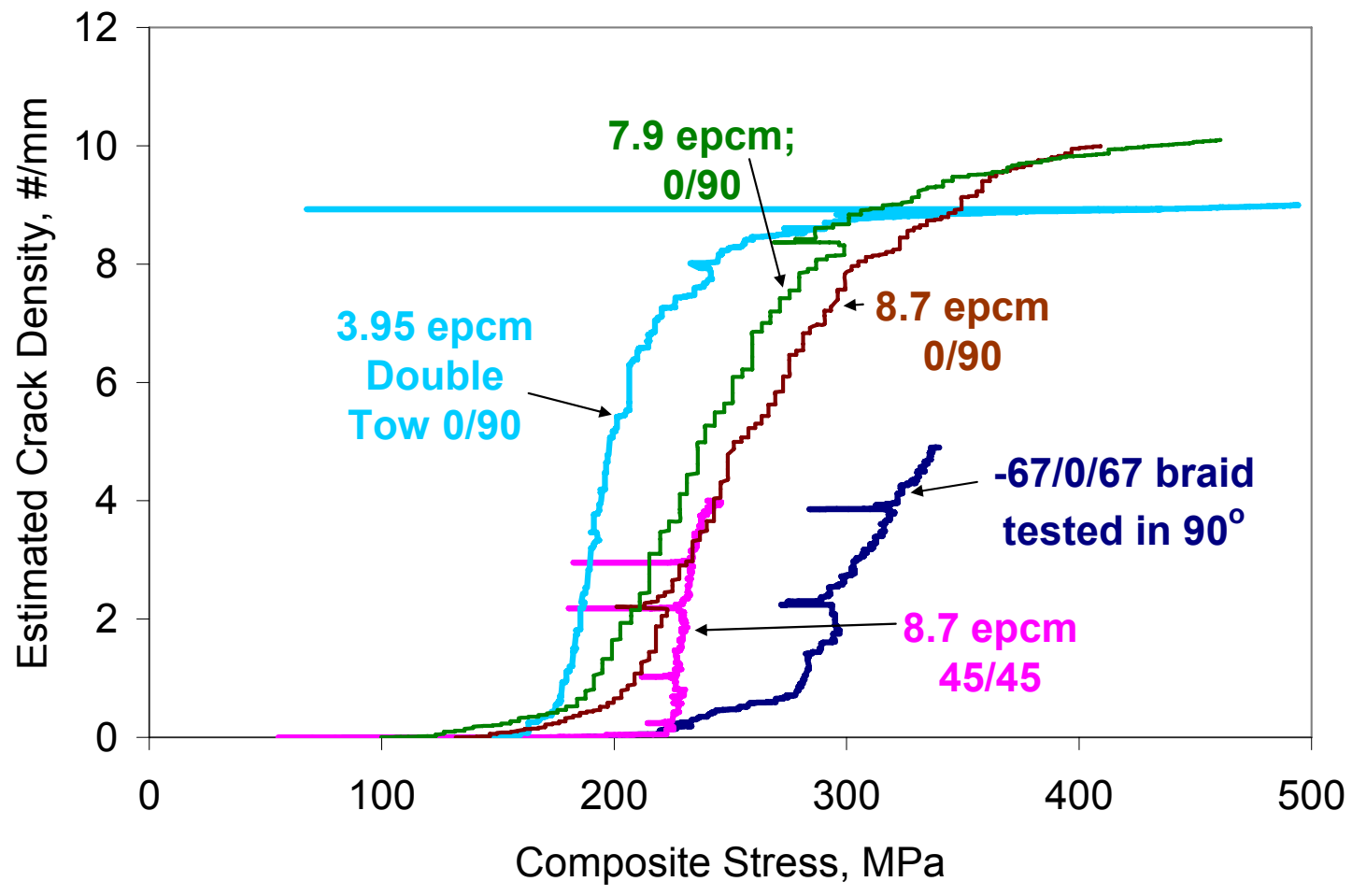

Figure 5: Estimated matrix crack density with stress based on AE. 


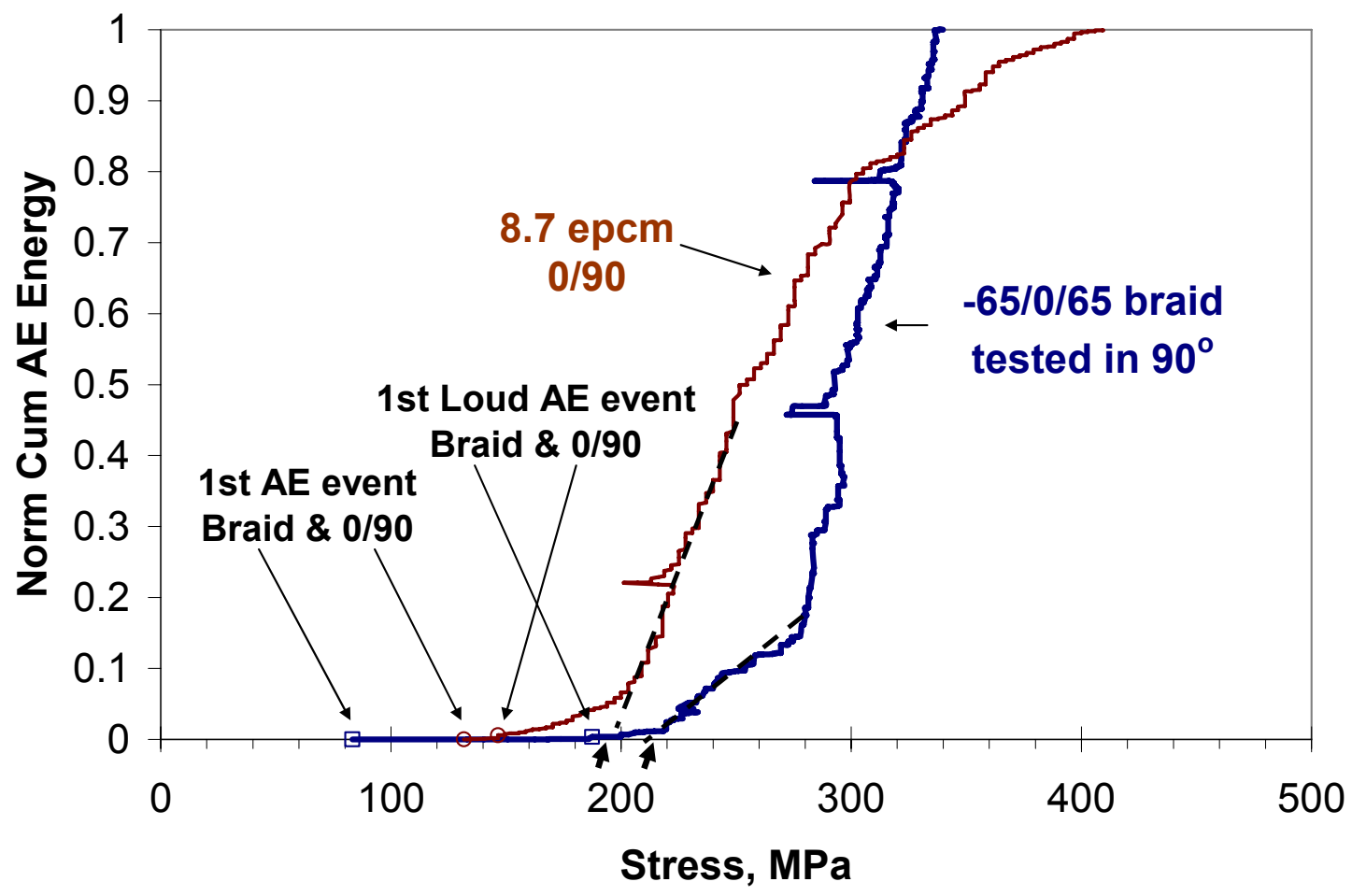

Figure 6: AE events and onset stress determination. The arrows below the $\mathrm{x}$-axis indicate AE onset stress. 


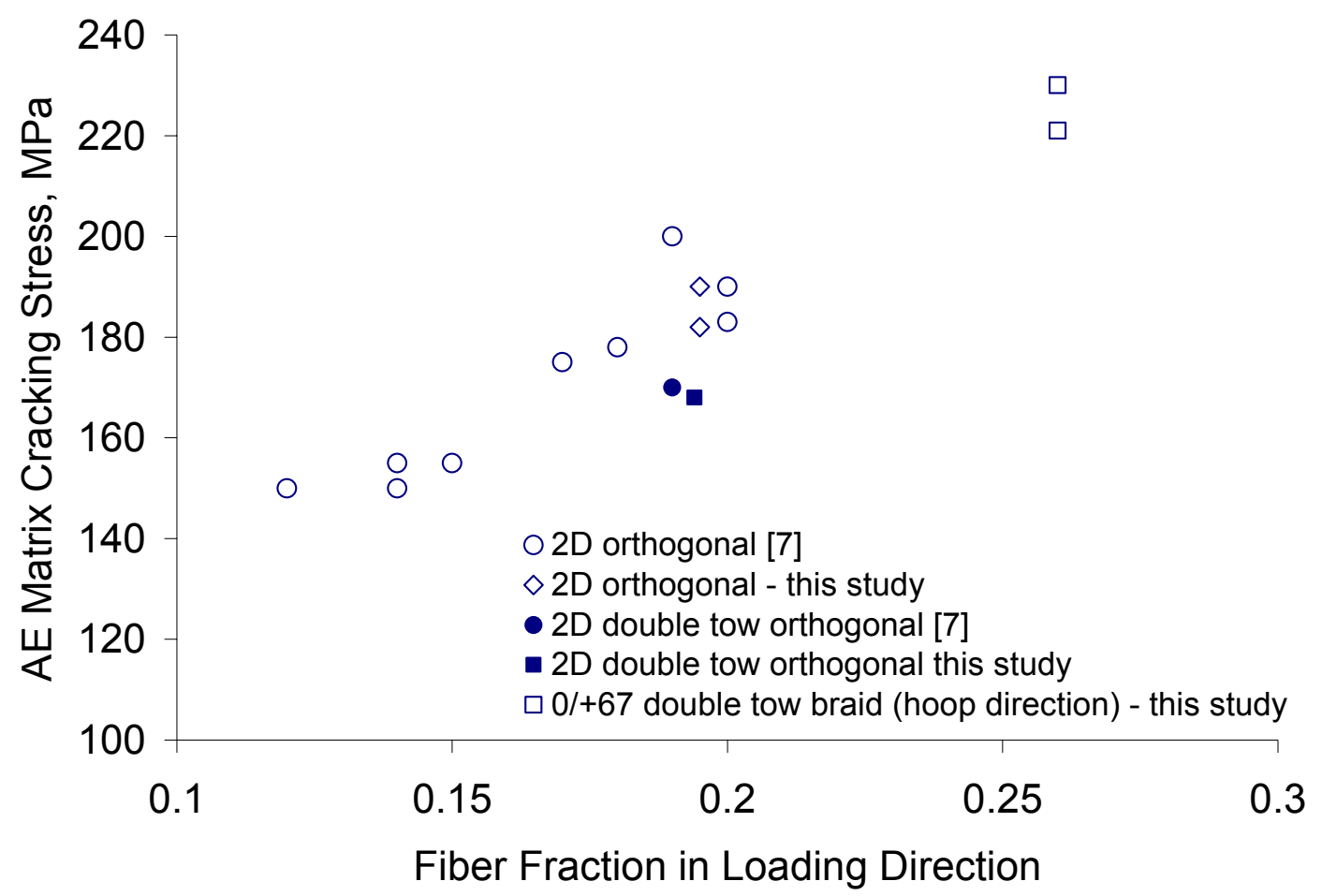

Figure 7: Effect of fiber fraction in the loading direction on AE matrix cracking (onset) stress for 2D composites with fibers tows oriented perpendicular to the loading direction. 


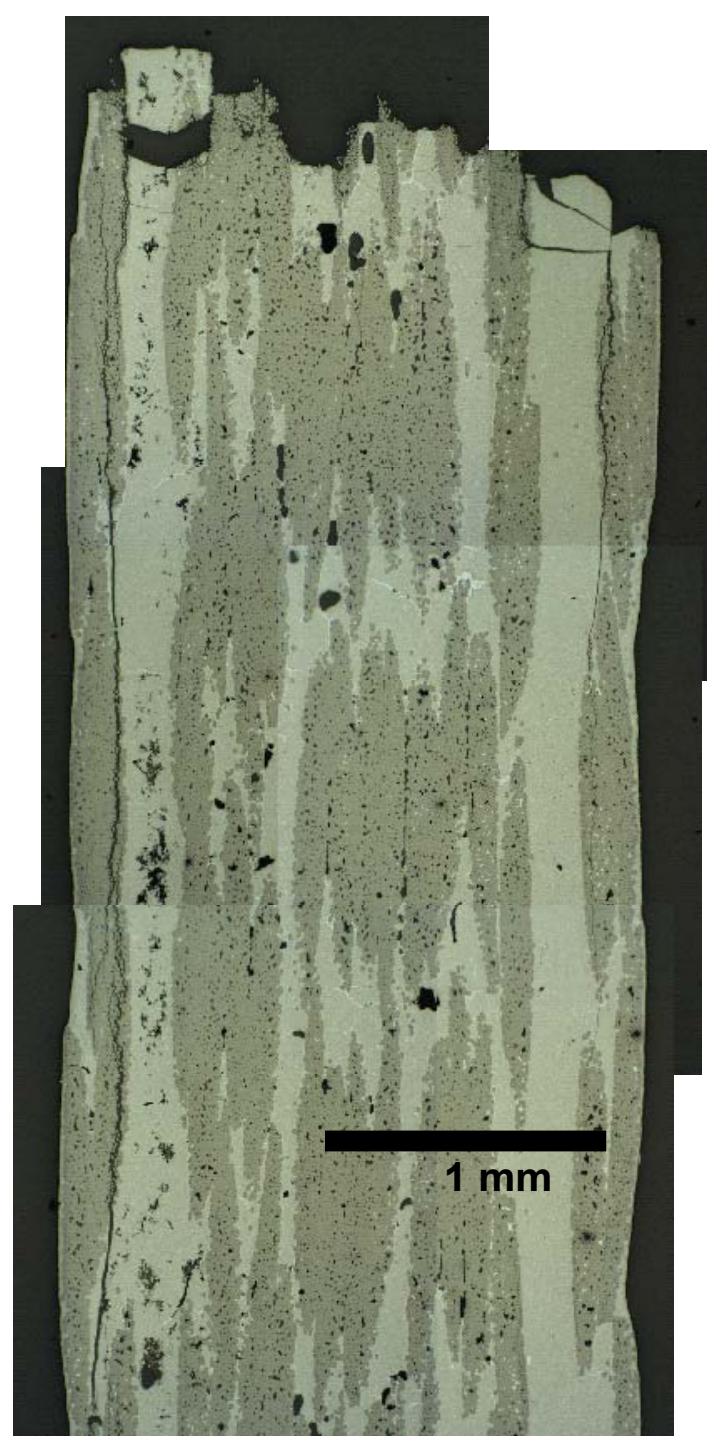

Figure 8: Micrograph of a 2D woven 45/45 oriented composite after RT tensile failure. 


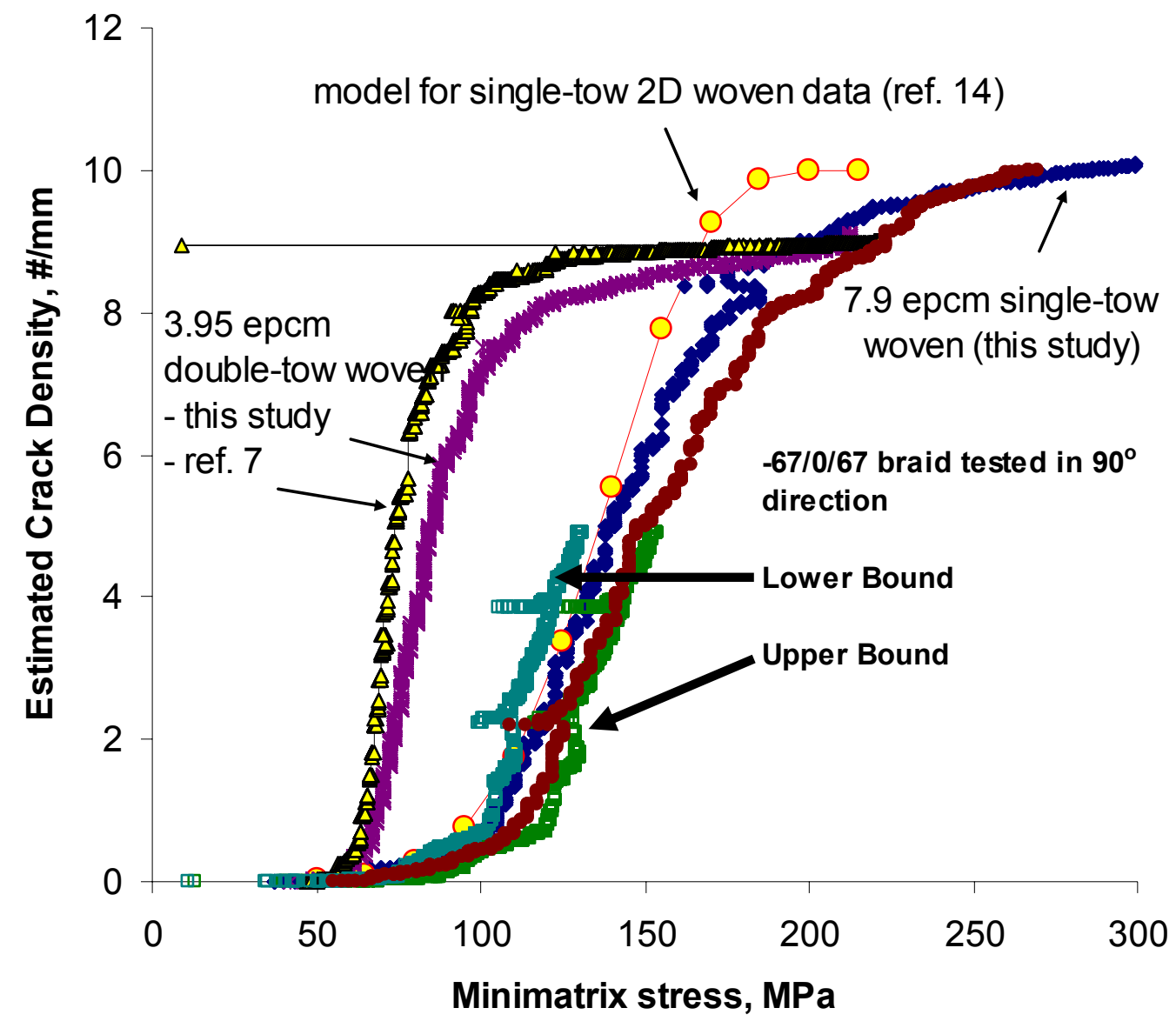

Figure 9: Estimated matrix crack density versus minimatrix stress. 


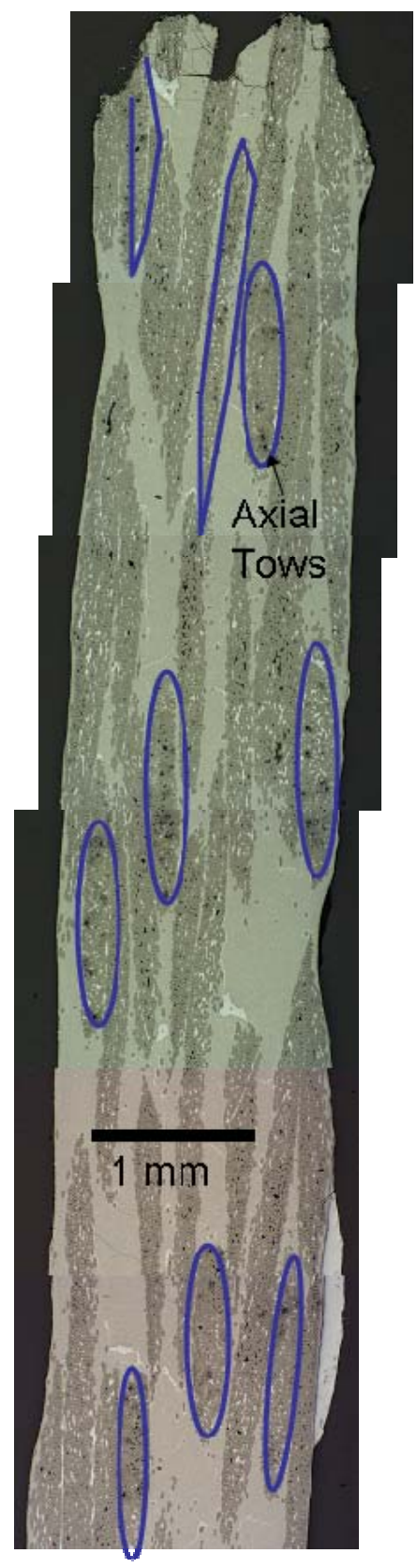

Figure 10: Micrograph of a triaxial braid composite after RT tensile failure. 


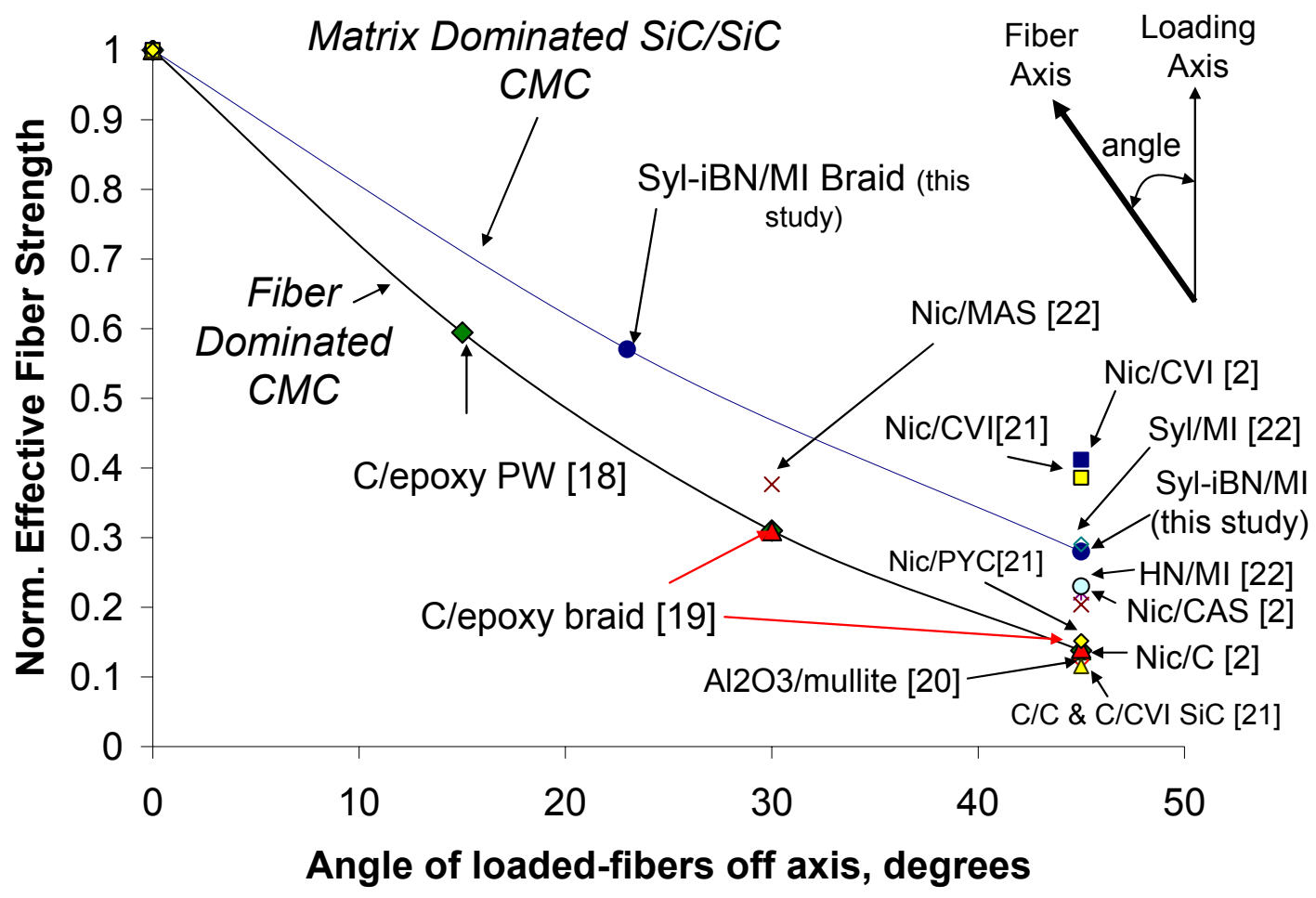

Figure 11: Effect of testing direction and composite type on the relative strength retention of the fibers for the composite data in Tables I, III, and IV. 